\title{
Multivariate optimization approach for the separation of water-soluble vitamins and related compounds by capillary electrophoresis
}

\author{
L. Fotsing, ${ }^{1 *}$ B. Boulanger, ${ }^{2}$ P. Chiap, ${ }^{1}$ M. Fillet, ${ }^{1}$ Ph. Hubert ${ }^{1}$ and J. Crommen ${ }^{1}$ \\ ${ }^{1}$ Department of Analytical Pharmaceutical Chemistry, Institute of Pharmacy, University of Liège, CHU, B36, B-4000 Liège 1, Belgium \\ ${ }^{2}$ Lilly Development Centre, Statistical Department, Rue Granbompré 11, B-1348 Mont-Saint-Guibert, Belgium
}

Received 28 May 1999; accepted 14 June 1999

\section{INTRODUCTION}

Due to its high separation efficiency and its different selectivity, capillary electrophoresis (CE) has proved to be useful as a complementary technique to liquid chromatography for the determination of drug-related impurities.

In contrast to the univariate approach (i.e. a systematic variation of a single parameter while maintaining the other factors constant), experimental designs involve a simultaneous alteration of all variables according to a predefined matrix of experiments. The multivariate approach allows optimum conditions to be obtained with a minimum number of experiments.

In order to determine simultaneously by $\mathrm{CE}$ a series of water-soluble vitamins, such as thiamine, riboflavin, nicotinamide, adenine, pantothenic acid, pyridoxine, ascorbic acid, biotin, rutin and $p$-aminobenzoic acid, and some related compounds, such as lumiflavine, nicotinic acid, pyridoxamine and thiamine monophosphate, experimental designs have been applied.

\section{RESULTS}

Using a D-optimal design with six factors (Atkinson and Doner, 1992), a CE method for the determination of thiamine, riboflavine, nicotinamide, pantothenic acid, pyridoxine and ascorbic acid was first optimized. The factors to be examined were type of buffer (borate, citrate and phosphate); concentration of buffer (from 25 to $75 \mathrm{mM}$ ); $\mathrm{pH}$ of buffer (3-9); percentage of methanol in buffer $(0-40 \%)$; applied voltage $(15-30 \mathrm{kV})$; and temperature $\left(20-40^{\circ} \mathrm{C}\right)$. The response criteria were peak resolutions and analysis time. To evaluated these criteria,

*Correspondence to: L. Fotsing, Department of Analytical Pharmaceutical Chemistry, Institute of Pharmacy, University of Liège, CHU, B36, B-4000 Liège 1, Belgium.

E-mail: L.Fotsing@ulg.ac.be migration times at the beginning, apex and end of the peak were measured.

A Derringer's desirability function including peak resolution and analysis time was used in order to deduce optimum and robust conditions within the experimental domain. The following optimum conditions were deduced: $62 \mathrm{mM}$ borate buffer adjusted to $\mathrm{pH} 9$; applied voltage $22.5 \mathrm{kV}$; temperature: $20^{\circ} \mathrm{C}$. Then, in order to separate simultaneously a series of water-soluble vitamins, and their related compounds (including neutral molecules), a micellar electrokinetic chromatography (MEKC) method, using a full factorial design (Massart et al., 1997) with two factors [sodium dodecyl sulphate (SDS) concentration and methanol proportion in buffer] at three levels (quadratic model) was applied (Table 1). The response criteria were modelled using a quadratic polynomial including interactions.

A multicriteria decision method (Derringer's desirability function) including the maximization of the minimum peak resolution and minimization of the maximum migration time was also used to deduce optimal and robust conditions within the experimental domain.

A $62 \mathrm{~mm}$ borate buffer (pH 9) containing $100 \mathrm{mM}$ of SDS and no methanol was found to be well suited for the

Table 1. Full factorial design for MEKC optimization

\begin{tabular}{lcc}
\hline Experiment & SDS concentration & $\begin{array}{c}\text { Percentage of organic } \\
\text { solvent }\end{array}$ \\
\hline 1 & 0 & 0 \\
2 & 0 & 5 \\
3 & 0 & 20 \\
4 & 50 & 0 \\
5 & 50 & 5 \\
6 & 50 & 20 \\
7 & 100 & 0 \\
8 & 100 & 5 \\
9 & 100 & 20 \\
\hline
\end{tabular}




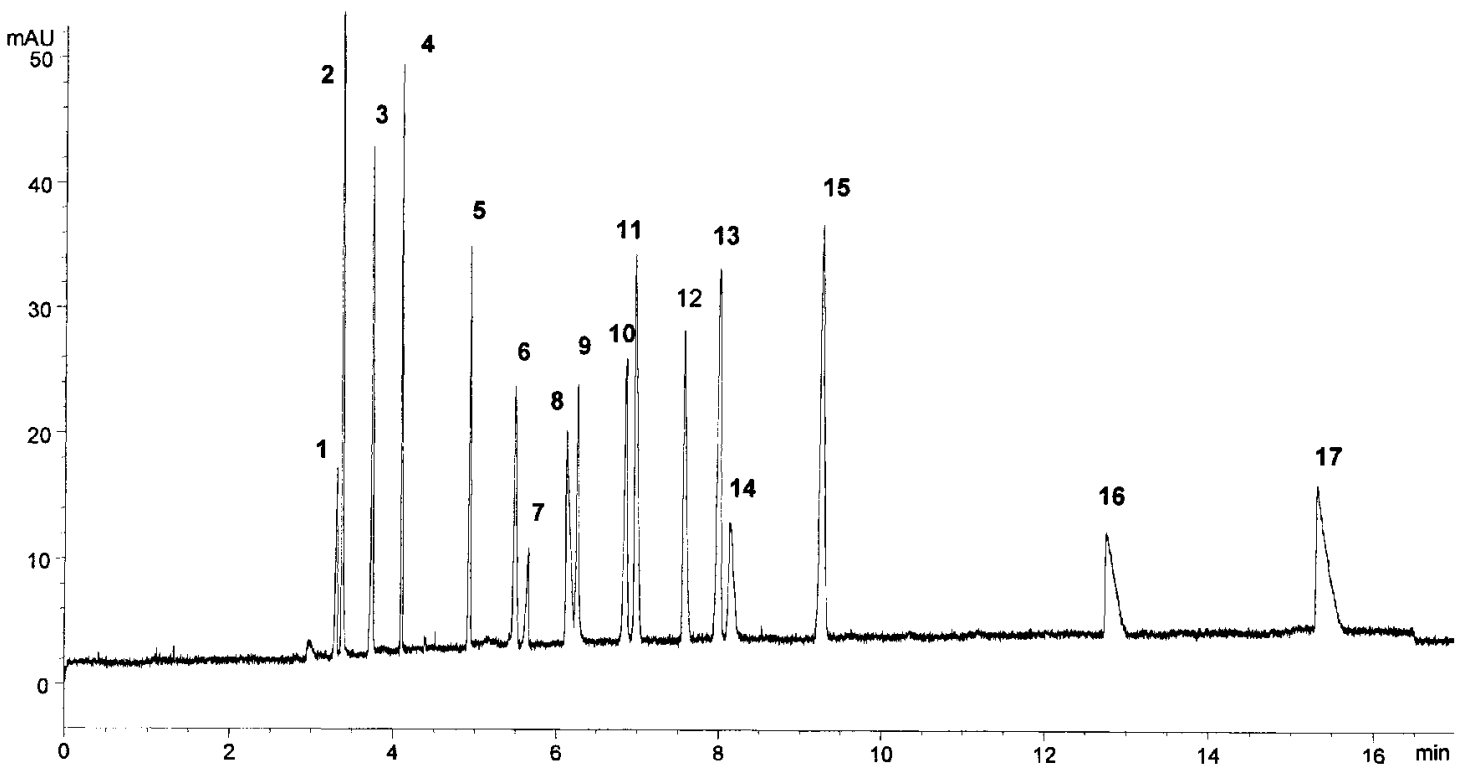

Figure 1. Experimental MEKC electropherogram. Buffer, $62 \mathrm{mM}$ borax adjusted to pH 9 with boric acid, containing $100 \mathrm{mM}$ of SDS detection wavelength $215 \mathrm{~nm}$; applied voltage, $22.5 \mathrm{kV}$; temperature, $20^{\circ} \mathrm{C}$. Peaks: $\mathbf{1}$, unknown peak of lumiflavine; $\mathbf{2}$, pyridoxamine; $\mathbf{3}$, nicotinamide; $\mathbf{4}$, adenine; $\mathbf{5}$, thiamine diphosphate; $\mathbf{6}$, pyridoxine; 7, Biotin; 8, riboflavine; 9, rutin; 10, pyridoxic acid; 11, cyanocobalamin; 12, PABA; 13, ascorbic acid; 14, pantothenic acid; 15, nicotinic acid; 16, lumiflavine; 17, thiamine.

MEKC separation of the 16 compounds examined in $16 \mathrm{~min}$. The separation was achieved in 16 min (Fig. 1).

In comparison with the CE method, the MEKC method was preferable. Indeed, with the latter vitamins can be separated from their related compounds, including neutral molecules.

The developed MEKC method was entirely validated. Good results with respect to selectivity, linearity, accuracy and precision were obtained.

The validated method was applied to the determination of water-soluble vitamins in different multivitamin formulations. The results confirm the real potentiality of $\mathrm{CE}$ as an alternative technique to the simultaneous determination of water-soluble vitamins and their main related compounds.

\section{REFERENCES}

Atkinson A. C. and Donev A. N., 1992. In: Optimum Experimental Design, Oxford University Press, Oxford.

Massart D. L., Vandeginste B. G. M., Buydens L. M. C., De Jong S. Lewi P. J. and Smeyers-Verbeke J., 1997. In: Handbook of Chemometrics and Qualimetrics: Part A, Elsevier, Amsterdam. 